ORIGINAL ARTICLE

\title{
Epidemiology of sleep disorders in the elderly - A questionnaire survey
}

\author{
J. C. Suri' ${ }^{1}$ M. K. Sen${ }^{1}$, U. C. Ojha ${ }^{2}$, Tulsi Adhikari ${ }^{3}$ \\ ${ }^{1}$ Department of Pulmonary, Critical Care \& Sleep Medicine, Vardhman Mahavir Medical College and \\ Safdarjang Hospital, N ew Delhi; ${ }^{2}$ ESI Hospital, Basaidarapur, New Delhi; ${ }^{3} \mathrm{~N}$ ational Institute of Medical \\ Statistics, ICMR, N ew Delhi.
}

Indian J Sleep Med 2009; 4.1, 12-18

\begin{abstract}
A questionnaire based survey was conducted to determine the prevalence of common sleep-related disorders in the elderly population of Delhi. The study population included in this analysis comprised 1240 grandparents of school-going children. The overall prevalence of SDB was $10.3 \%$.; (9.9\% in males and $10.8 \%$ in female subjects) It was found to correlate with increasing BMI $(p<0.064)$ The overall prevalence of snoring was found to be $41.4 \%$ (Males $=41.6 \%$, Females $=41.2 \%$ ). It correlated positively with body mass index (BMI) $(p<0.033)$, age $(p<0.076)$, and excessive daytime sleepiness $(p<0.036)$. Habitual snoring was found to be prevalent in $27.2 \%$ of the elderly subjects and was found to correlate with BMI $(p<0.03)$, and rising socio-economic strata $(p<0.014)$. Approximately $41.5 \%$ of the elderly population was seen to suffer from excessive daytime sleepiness. It correlated significantly with lower socio-economic strata The overall prevalence of symptoms suggestive of restless leg syndrome was $14.3 \%$. It was found to correlate significantly with BMI $(p<0.018)$, and female gender $(p<0.052)$ The overall prevalence of sleepwalking in the elderly population studied was $6.9 \%$. It was found to correlate negatively with increasing BMI $(p<0.041)$ and age and positively with rising socio-economic strata $(p<0.076)$. The prevalence of nightmares in the elderly population studied was $21.7 \%$. It was found to correlate inversely with age $(p<0.019)$. Bruxism was observed to be present in $9.2 \%$ of the elderly population studied. It correlated significantly with rising socio-economic strata $(p<0.017)$ and snoring $(p<0.002)$. Approximately $8 \%$ of the entire elderly study population admitted that they consumed sleeping pills. Its use correlated with rising socio-economic strata $(p<0.033)$ and symptoms suggestive of disorders of initiation \& maintenance of sleep (DIMS) ( $p<0.072$ ).

Keywords: elderly, snoring, sleep-disordered breathing (SDB), Excessive daytime sleepiness, Restless leg syndrome (RLS), sleepwalking, nightmares, bruxism, Disorders of initiation and maintenance of sleep (DIMS), SES (Socio economic strata)
\end{abstract}

\section{Introduction}

A questionnaire based survey was conducted to determinetheprevalence of common sleep-related disorders in an elderly population of $D$ elhi. The

Address for correspondence:

\section{Dr. J. C. Suri}

Senior Chest Physician \& Head-Dept of Pulmonary, Critical Care \& Sleep Medicine, Safdarjang Hospital, New Delhi. E-mail: jcsuri@ rediffmail.com

Indian Journal of Sleep M edicine (IJSM), Vol. 4, N o. 1, 2009
N ational C apital Region (N CR) is themetropolitan area of D elhi comprising cities likeFaridabad, G urgaon, G haziabad and $\mathrm{N}$ oida. Thepopulation of this region is approximately 12.8 million that resides in area of nearly $1483 \mathrm{sq} \mathrm{km}$.

\section{Material and Methods}

The study population included in this analysis comprised the grandparents of school-going children. The latter were randomly selected for inclusion from another study, 
the results of which were published earlier in thejournal as a part of a family survey ${ }^{(1)}$. In addition to a set of two child questionnaires (one for the child and another for his/her sibling) a second set of two other elderly questionnaires (one each to befilled up by thegrandparents) werealso handed over to each child. Informed consent was duly obtained from each participant. A covering letter from thePrincipal Investigator that was addressed to theparents was included in the set. Two different types of schools were selected for recruitment of subjects. O ne type of schools catered to children from the relatively middle and upper classes of society; the other comprised children from the relatively lower and economically challenged section. This was deliberately so designed so as to cover a fairly large socioeconomic cross-section of thepopulation.

The field investigator duly explained the procedure for filling up thequestionnaire and extended all possiblehelp in answering it. A total of 4000 questionnaires were distributed of which 1376 were received back. And finally 1240 questionnaires were selected for analysis as they satisfied all criteria for acceptance. Appropriate statistical methods were applied using SPSS software.

\section{The questionnaire}

The questionnaire used for the purposes of this study was adapted from those by Chervin and the Stanford Sleep Clinic questionnaire ${ }^{(2,3)}$ It included questions pertaining to demography, any past and present medical problem, family history of snoring, sleep terror, and nightmare.

It also included questions pertaining to snoring, excessive daytime sleepiness (Epworth sleepiness score), sleep disordered breathing, disorders of initiation and maintenance of sleep, restless legs syndrome and sleep deprivation. The total number of questions in the questionnaire was 39 in addition to questions pertaining to past/present medical problems, if any.

A randomly selected sub-group of forty subjects in whom any sleep disorder was diagnosed, on the basis of their response to the questionnaire, were also examined clinically in theSleep C linic. Sensitivity and specificity scores, compared with clinical diagnosesfrom theSleep Clinic, were good for all sleep disorders namely, SD B (sleep disordered breathing), disorders of initiation and maintenance of sleep, restless legs, sleepwalking, sleep-bruxism and nightmares. Theagreement between clinical diagnoses and questionnaire classification of sleep disorders was thus observed to begood.

\section{Interpretation}

Sleep disordered breathing (SD B) was clinically suspected if, in a subject with habitual snoring in whom breathing pauses were noticed and in whom the Epworth Sleepiness Score (ESS) was $>10$

A subgroup of 95 subjects (anumber that was considered to be statistically significant) was randomly selected from thetotal pool of adultsthat reported snoring and werethen subjected to wholenight in-lab supervised polysomnography (PSG) (Alice 5, Respironics, M urrysville, PA). The PSG study was conducted on snoring adults only because, (a) snoring was a high risk factor for SD B; (b) it was extremely difficult to convincea normal adult who had volunteered to respond to the questionnaire to undergo PSG. O $\mathrm{n}$ the basis of theresults obtained from this sample, the prevalence of SD B in the whole population was calculated. This method may have missed some cases of SD B who underreported snoring. Thefollowing parametersweremeasured: 2 channels seach for electroencepholography (EEG); electrooculography (EOG); and electromyography (EM G); airflow recording through nose and mouth by thermistor and nasal pressure cannula; thoracic and abdominal efforts by plethysmography; oxygen saturation through pulse oximetery; and tracheal sound recording by using a microphone attached to theneck.

0 bstructive apnea was defined as cessation of airflow at thenoseand mouth, as measured by thermistor/ nasal canula whiletherespiratory effort continued for at least ten seconds. $\mathrm{H}$ ypopnea was scored when the nasal pressure signal excursions dropped by $\geq 50 \%$ of the baseline for a duration of at least 10 seconds and was associated with a drop of saturation of $\geq 3 \%$ from the pre-event baseline or if it was associated with arousal (4) Respiratory effort related arousal (RERA) was scored when there was a sequence of breaths lasting at least ten seconds characterized by increasing respiratory effort or flattening of the nasal pressure waveform, leading to an arousal from sleep when the sequence of breaths did not meet the criteria for an apnea or hypopnea. ${ }^{(4)}$ Excessive daytime sleepiness (ED S) was scored in thepresence of questionnaire response of excessive daytime sleepiness along with Epworth Sleepiness Score (ESS) of $\geq 10$. SD B was diagnosed when a patient with symptomssuggesting SD B hasan RDI (apneas +hypopneas +RERAs) was $>5$ per hour. Snoring adults with RD I of less than or equal to five hours of total sleep time (TST ) with no clinically significant hypoxemia, hypercapnia or excessive daytimesleepiness wereconsidered to haveprimary snoring (5). The diagnosis of other sleep disorders (such as restlessleg 
syndrome, bruxism, nightmare, sleepwalking and disorders of initiation and maintenance of sleep) was based on the criterialaid down in the International Classification of Sleep $D$ isorders-D iagnostic \& Scoring manual ${ }^{(6)}$

\section{Statistical Methods}

All the data analysis was performed using statistical software SPSS 11.0, Chi-square test and t-test were used to determine significance of correlation and testing the differences in the prevalences by characteristics.

\section{Results}

The overall prevalence of various sleep disorders in the elderly is depicted in Table 1.

Table 1: 0 verall prevalence of sleep disorders amongst theelderly in the community

\begin{tabular}{|l|l|l|l|l|}
\hline \multirow{2}{*}{ S.N } & Sleep D isorder & \multicolumn{3}{|l|}{ Prevalence(\%) } \\
\cline { 3 - 5 } & & Total & M ale & Female \\
\hline 1 & Snoring & 41.4 & 41.6 & 41.2 \\
\hline 2 & H abitual snoring & 27.2 & 24.8 & 30.3 \\
\hline 3 & $\begin{array}{l}\text { Sleep disordered } \\
\text { breathing }\end{array}$ & 10.3 & 9.9 & 10.8 \\
\hline 4 & $\begin{array}{l}\text { Excessive daytime } \\
\text { sleepiness }\end{array}$ & 41.5 & 43 & 40 \\
\hline 5 & Restless leg syndrome & 14.3 & 10.1 & 17.6 \\
\hline 6 & Sleepwalking & 6.9 & 5.4 & 6.7 \\
\hline 7. & N ightmare & 21.7 & 17.4 & 23.5 \\
\hline 8. & Bruxism & 10.6 & 11.4 & 7.6 \\
\hline 9. & $\begin{array}{l}\text { Consumption of } \\
\text { sleeping pills }\end{array}$ & 8 & 8.7 & 7 \\
\hline 10. & $\begin{array}{l}\text { Disorders of initiation } \\
\text { \& maintenance of sleep } \\
\text { (DIM S) }\end{array}$ & 59 & 50 & 63.5 \\
\hline
\end{tabular}

\section{Snoring}

The overall prevalence of snoring was found to be $41.4 \%$ ( $M$ ales $=41.6 \%$, Females $=41.2 \%$ ). It correlated positively with body mass index (BM I) $(p<0.033)$, age $(p<0.076)$, and excessive daytime sleepiness $(p \varangle 0.036)$. (Table 2$)$. $\mathrm{H}$ abitual snoring was found to be prevalent in $27.2 \%$ of the elderly subjects. (Table 3). It was again found to correlate with BMI ( $p \ll 0.03)$, and rising socio-economic strata $(p<0.014)$

Indian Journal of Sleep M edicine (IJSM ), Vol. 4, N o. 1, 2009
Table 2 : Snoring(\%) and its correlates

\begin{tabular}{|l|l|l|l|l|l|}
\hline \multicolumn{5}{|c|}{ Snoring $=41.4 \%$} & p-value \\
\hline \multicolumn{7}{|c|}{ BM I } & $\begin{array}{l}<18.5 \\
34.6\end{array}$ & $\begin{array}{l}(18.5-24.9) \\
34.8\end{array}$ & $\begin{array}{l}(25-29.9) \\
43.9\end{array}$ & $\begin{array}{l}(>=30) \\
55.6\end{array}$ & 0.033 \\
\hline SES & Low & High & & & \\
& 42 & 40.9 & & & 0.479 \\
\hline Sex & $\begin{array}{l}\text { M ale } \\
41.6\end{array}$ & $\begin{array}{l}\text { Female } \\
41.2\end{array}$ & & & \\
\hline Age & $60-70$ & $71-80$ & $>80$ & & 0.521 \\
\hline EDS & 38 & 42.3 & 57.1 & & 0.076 \\
\hline & Yes & N o & & & \\
\hline
\end{tabular}

Table 3: Prevalenceof habitual snoring (\%) and itscorrelates

\begin{tabular}{|l|l|l|l|l|l|}
\hline \multicolumn{2}{|c|}{ H abitual snoring $=27.2 \%$} & p-value \\
\hline BM I & $<18.5$ & $(18.5-24.9)$ & $(25-29.9)$ & $(>=30)$ & \\
& 19.2 & 20.2 & 30.3 & 44.4 & 0.03 \\
\hline SES & Low & High & & & \\
& 18.2 & 31.5 & & & 0.014 \\
\hline Sex & M ale & Female & & & \\
& 24.8 & 30.3 & & & 0.197 \\
\hline Age & $60-70$ & $71-80$ & $>80$ & & \\
& 28.8 & 23.1 & 28.6 & & 0.632 \\
\hline
\end{tabular}

\section{Sleep Disordered Breathing (SDB)}

Theoverall prevalence of SD B was $10.3 \%$.; ( $9.9 \%$ in males and $10.8 \%$ in female subjects) It was found to correlate with increasing BMI $(p<0.064)$ (Table4).

Table 4: Sleep disordered breathing (\%) and its correlates

\begin{tabular}{|l|l|l|l|l|l|}
\hline \multicolumn{5}{|c|}{ SD B $=10.3 \%$} \\
\hline \multirow{2}{*}{ BM I } & $<18.5$ & $18.5-24.9$ & $25-29.9$ & $>=30$ & p-value \\
\hline & 9.3 & 8.2 & 11 & 15 & 0.064 \\
\hline \multirow{2}{*}{ SES } & Low & High & & & 0.226 \\
& 11.3 & 9.8 & & & \\
\hline SEX & $\begin{array}{l}\text { M ale } \\
9.9\end{array}$ & $\begin{array}{l}\text { Female } \\
10.8\end{array}$ & & & 0.614 \\
\hline Age & $\begin{array}{l}60-70 \\
\text { W }\end{array}$ & $\begin{array}{l}71-80 \\
10.7\end{array}$ & $>80$ & & \\
\hline W ith morning tiredness & 6.7 & & \\
\hline W ith mood changes & 5.1 & & \\
\hline
\end{tabular}




\section{Excessive daytime sleepiness:}

Approximately $41.5 \%$ of the elderly population was seen to suffer from excessive daytime sleepiness. It correlated significantly with lower socio-economic strata (Table 5).

Table5 : Excessivedaytimesleepiness (\%) and its correlates

\begin{tabular}{|l|l|l|l|l|l|}
\hline \multicolumn{5}{|l|}{ ED $=41.5$} \\
\hline BM I & $\begin{array}{l}<18.5 \\
58.8\end{array}$ & $\begin{array}{l}(18.5-24.9) \\
38.6\end{array}$ & $\begin{array}{l}(25-29.9) \\
42.3\end{array}$ & $\begin{array}{l}(>=30) \\
52\end{array}$ & 0.409 \\
\hline SES & $\begin{array}{l}\text { Low } \\
70\end{array}$ & $\begin{array}{l}\text { High } \\
29.3\end{array}$ & & & \\
\hline Sex & $\begin{array}{l}\text { M ale } \\
43\end{array}$ & $\begin{array}{l}\text { Female } \\
40\end{array}$ & & & 0 \\
\hline Age & $\begin{array}{l}60-70 \\
74.5\end{array}$ & $\begin{array}{l}71-80 \\
34.5\end{array}$ & $\begin{array}{l} \\
40\end{array}$ & & 0.394 \\
\hline
\end{tabular}

\section{Restless leg syndrome (RLS)}

The overall prevalence of symptoms suggestive of restless leg syndromewas $14.3 \%$ (Table6). It wasfound to correlate significantly with BMI $(p<0.018)$, and female gender $(p \varangle 0.052)$

Table 6 : Restless les syndrome (\%) and its correlates

\begin{tabular}{|c|c|c|c|c|c|}
\hline \multicolumn{6}{|c|}{$\mathrm{RLS}=14.3$} \\
\hline & & & & & $p$-value \\
\hline \multirow[t]{2}{*}{ BM I } & $<18.5$ & $(18.5-24.9)$ & $(25-29.9)$ & $(>=30)$ & \\
\hline & 7.7 & 7.9 & 18.2 & 27.8 & 0.018 \\
\hline \multirow[t]{2}{*}{ SES } & Low & High & & & \\
\hline & 12.5 & 13.8 & & & 0.464 \\
\hline \multirow[t]{2}{*}{ Sex } & $M$ ale & Female & & & \\
\hline & 10.1 & 17.6 & & & 0.052 \\
\hline \multirow[t]{2}{*}{ Age } & $60-70$ & $71-80$ & $>80$ & & \\
\hline & 12.9 & 11.5 & 21.4 & & 0.401 \\
\hline
\end{tabular}

\section{Sleepwalking}

The overall prevalence of sleepwalking in the elderly population studied was $6.9 \%$ (Table 7). It was found to correlate negatively with increasing BM I $(p \ll 0.041)$ and age and positively with rising socio-economic strata $(p<0.076)$.
Table 7 : Sleep walking (\%) and its correlates

\begin{tabular}{|c|c|c|c|c|c|}
\hline \multicolumn{6}{|c|}{ Sleep walking= 6.9} \\
\hline & & & & & p-value \\
\hline \multirow[t]{2}{*}{ BM I } & $<18.5$ & $(18.5-24.9)$ & $(25-29.9)$ & $(>=30)$ & \\
\hline & 15.4 & 10.1 & 1.5 & 2.8 & 0.041 \\
\hline \multirow[t]{2}{*}{ SES } & Low & $\mathrm{High}$ & & & \\
\hline & 2.3 & 7.7 & & & 0.076 \\
\hline \multirow[t]{2}{*}{ Sex } & $M$ ale & Female & & & \\
\hline & 5.4 & 6.7 & & & 0.796 \\
\hline \multirow[t]{2}{*}{ Age } & $60-70$ & $71-80$ & $>80$ & & \\
\hline & 4.3 & 7.7 & 10.7 & & 0.308 \\
\hline
\end{tabular}

\section{Nightmare}

The prevalence of nightmares in the elderly population studied was $21.7 \%$ (Table 8 ). It was found to correlate inversely with age $(p<0.019)$. However, no significant correlation was observed with BM I.

Table 8 : N ightmare (\%) and its correlates

\begin{tabular}{|l|l|l|l|l|l|}
\hline \multicolumn{5}{|l|}{ N ightmare $=21.7$} \\
\hline \multicolumn{7}{|c|}{ BMI } & $<18.5$ & $(18.5-24.9)$ & $(25-29.9)$ & $\begin{array}{l}(>=30) \\
33.3\end{array}$ & 0.167 \\
& 26.9 & 20.2 & 15.2 & -value \\
\hline SES & Low & High & & & \\
& 19.3 & 20.4 & & & 0.483 \\
\hline Sex & M ale & Female & & & \\
& 17.4 & 23.5 & & & 0.14 \\
\hline Age & $60-70$ & $71-80$ & $>80$ & & \\
& 22.7 & 10.3 & 32.1 & & 0.019 \\
\hline
\end{tabular}

\section{Bruxism}

Bruxism was observed to be present in $9.2 \%$ of the elderly population studied (Table 9). It correlated significantly with rising socio-economic strata $(p \varangle 0.017)$ and snoring $(p \varangle 0.002)$.

\section{Consumption of sleeping pills}

Approximately $8 \%$ of the entire elderly study population admitted that they consumed sleeping pills (Table10). Its use correlated with rising socio-economic strata $(p<0.033)$ and symptoms suggestive of disorders of initiation \& maintenance of sleep (DIMS) $(p \varangle 0.072)$.

Indian Journal of Sleep M edicine (IJSM ), Vol. 4, N o. 1, 2009 
Table 9 : Bruxism (\%) and its correlates

\begin{tabular}{|c|c|c|c|c|c|}
\hline \multicolumn{6}{|c|}{ Bruxism = 10.6} \\
\hline & & & & & $p$-value \\
\hline \multirow[t]{2}{*}{ BMI } & $<18.5$ & (18.5-24.9) & $(25-29.9)$ & $(>=30)$ & \\
\hline & 15.4 & 14.6 & 7.6 & 2.8 & 0.165 \\
\hline \multirow[t]{2}{*}{ SES } & Low & $\mathrm{High}$ & & & \\
\hline & 4.3 & 12.2 & & & 0.034 \\
\hline \multirow[t]{2}{*}{ Sex } & M ale & Female & & & \\
\hline & 11.4 & 7.6 & & & 0.199 \\
\hline \multirow[t]{2}{*}{ Age } & $60-70$ & $71-80$ & $>80$ & & \\
\hline & 6.7 & 11.5 & 21.4 & & 0.042 \\
\hline
\end{tabular}

Table 10: Consumption of sleeping pills(\%) and its correlates

\begin{tabular}{|c|c|c|c|c|c|}
\hline \multicolumn{6}{|c|}{ Sleeping Pills = 8\% } \\
\hline & & & & & $p$-value \\
\hline \multirow[t]{2}{*}{ BM I } & $<18.5$ & $(18.5-24.9)$ & $(25-29.9)$ & $(>=30)$ & \\
\hline & 0 & 9.5 & 6.2 & 13.9 & 0.233 \\
\hline \multirow[t]{2}{*}{ SES } & Low & $\mathrm{H}$ igh & & & \\
\hline & 8.3 & 7 & & & 0.8 \\
\hline \multirow[t]{2}{*}{ Sex } & M ale & Female & & & \\
\hline & 6.5 & 8.6 & & & 0.634 \\
\hline \multirow[t]{2}{*}{ Age } & $60-70$ & $71-80$ & $>80$ & & \\
\hline & 4.6 & 10.7 & 14.3 & & 0.087 \\
\hline
\end{tabular}

\section{Disorders of initiation and maintenance of sleep (DIMS)}

Approximately $59 \%$ of the elderly population was observed to have complaints suggestive of disorders of initiation and maintenance of sleep .It was found to correlate with female gender $(p \varangle 0.013)$ (Tablel1)

Table 11: Prevalence of disorders of initiation $\&$ maintenance of sleep (DIM S) (\%) and its correlates

\begin{tabular}{|l|l|l|l|l|l|}
\hline \multicolumn{5}{|c|}{ D IM S = 59\% } \\
\hline \multicolumn{7}{|c|}{ BM I } & $\begin{array}{l}<8.5 \\
38.5\end{array}$ & $\begin{array}{l}(18.5-24.9) \\
64\end{array}$ & $\begin{array}{l}(25-29.9) \\
54.5\end{array}$ & $\begin{array}{l}(>=30) \\
77.8\end{array}$ & 0.011 \\
\hline SES & $\begin{array}{l}\text { Low } \\
50\end{array}$ & $\begin{array}{l}\text { H igh } \\
63.5\end{array}$ & & & \\
\hline Sex & & $\begin{array}{l}\text { M ale } \\
67.2\end{array}$ & Female & & 0.024 \\
\hline Age & 53 & $60-70$ & $71-80$ & $>80$ & 0.013 \\
\hline
\end{tabular}

\section{Discussion}

The elderly population experiences sleep problems quite commonly. Sleep quality, quantity, and architectureundergo changes with ageing. The ability to initiate and maintain sleep is associated with a decrease in theproportion of deeper, more restorative slow-wave sleep and REM sleep (28). This impaired ability to initiate and maintain sleep may be a marker of increased mortality and neuro-cognitive dysfunction. ${ }^{(28)}$ The mechanisms related to age-related changes in sleep include age-related modifications in circadian modulation, homeostatic factors, cardiopulmonary function, and endocrinefunction. O Ider subjects havemorenight-timearousals, awakenings, and sleep stage shifts. A reduction occurs in total sleep time, sleep efficiency, slow-wavesleep and the duration of nocturnal awakenings is increased ${ }^{(17)}$. Theremay al so beco-morbid conditions like medical and psychiatric disorders in thegeriatric agegroup. Social and environmental factors may also play a role in certain situations.

Comprehensiveepidemiological data on sleep disorders in the elderly is virtually non-existent in our country. It is with this background that a population-based study was undertaken in our center.

\section{Sleep-disordered breathing}

The prevalence of OSA (defined as AHI $\geq 5$ )is $9 \%$ for women and $24 \%$ in men aged $30-60$ years; and the prevalence of OSA syndrome (AHI $\geq 5$ and daytime hypersomnolence) is $2 \%$ for women and $4 \%$ for men. ${ }^{(7)}$ In adults more than 60 years old, the prevalence rates of OSA are significantly higher and ranges between $37.5 \%$ to $62 \%{ }^{(8,9)}$. A step-wise increase in the prevalence of sleepdisordered breathing was documented in the elderly population in another study; $2.9 \%$ of 60 -year olds, $33.3 \%$ of 70 -year olds and $39.5 \%$ of 80 -year olds having $\mathrm{AHI}$ of 5 or higher ${ }^{(10)}$. The Sleep H eart $\mathrm{H}$ ealth Study also found a similar stepwiseincreasein theprevalence of sleep-disordered breathing with increasing age ${ }^{(11)}$. Some studies opine that increased prevalence rates of SD B with rising age may be due to increased occurrence of central events; peaking at 55years age and then actually declining ${ }^{(12)}$. Theprevalence of sleep apnea $(\mathrm{AHI} \geq 10)$ has also been found to behigher in post-menopausal women than premenopausal women ( $47 \%$ vs $21 \%$ ); and post-menopausal women havealso been observed to be having a significantly higher mean AH I compared to pre- menopausal women after adjusting for body mass index and neck circumference (13). Similar 
trends have been observed in theW isconsin Sleep Cohort study and other studies ${ }^{(14-16)}$.

Age related changes, like increased adipose tissue deposition in upper airway, pharyngeal bony changes dueto remodeling, longer pharyngeal airway, diminished protective dilator reflexes against airway collapse, reduced upper airway occlusion during obstructive apnea, may all contribute to the increasing prevalence of SD B in the elderly ${ }^{(17)}$. D emented patients experience higher rates of OSA, perhaps dueto degenerativechanges in the respiratory and autonomic centers in the brainstem ${ }^{(18)}$. The prevalence of SD B (AHI $\left.\geq 5\right)$, in a survey of general population aged $50-70$ years, was $28.9 \%$ and that of a sleep apnea syndrome (SAS) was found to be $6.8 \%{ }^{(19)}$. The estimated prevalence of OSA among older adults may vary from $13 \%$ to $28 \%$ in men and $4 \%$ to $20 \%$ in women ${ }^{(8,17,31)}$. The prevalence of SD B in the present study was estimated to be $10.3 \%$; it was also found to correlate with increasing BMI $(p<0.064)$ (Table 4).

\section{Restless legs syndrome}

In elderly patients, the prevalence of restless legs syndrome (RLS) varies from $8.3 \%$ to $20 \%{ }^{(17,20-22)}$ and occurs more commonly in older women than in older

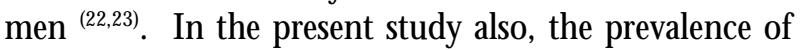
symptoms suggestive of RLS was $14.3 \%$ and it correlated significantly with female gender.

\section{Disorders of initiation and maintenance of sleep (DIMS)}

In the older adult population, the prevalence of insomnia has been reported to be between $20 \%$ and $40 \%(24,25)$. Its annual incidence is about 5\% (26). In a large sample of community-dwelling elders, approximately $50 \%$ of elderly subjects reported symptoms of insomnia at least few nights per week (27). In older adults, sleep tends to becomeshorter moreshallow and disrupted as evidenced by increased number of sleep stage shifts, arousals and awakening $(28,29)$. In the present study, the prevalence of DIM S was observed to be $59 \%$ and it correlated with female gender. In any case presenting with insomniathepossibility of physical illness disrupting sleep (cardiovascular, gastrointestinal, respiratory), age related complaints (prostatism), psychiatric disorders (depression, dementia) and iatrogenic causes (theophylline, diuretics) should be considered(30).

\section{Consumption of sleeping pills}

An increasein prescription and use of hypnotic drugs with age (10-15\%, among elderly people and higher among those over 75, women and those in hospital and old-age homes) has been often noted ${ }^{(30)}$. In the present study, approximately $8 \%$ of the entire elderly study population consumed sleeping pills, its usecorrelated with rising socioeconomic strata and symptomssuggestive of D IM S. Keeping in view the magnitude of the problem of DIM S $(59 \%$ approximately), the proportion of elderly subjects consuming sleeping pills was found to be much lower in this study as compared to theWestern population.

\section{Nightmares}

In one study the mean annual nightmare frequency was about $65 \%$ as high among elderly healthy subjects as compared to collegestudents; the elderly were about onefifth as likely as collegestudents to report a problem with nightmares ${ }^{(31)}$.

\section{Sleepwalking}

In theelderly, sleepwalking most often is associated with an organic brain syndrome, commonly nocturnal delirium ${ }^{(32)}$. In the present study the overall prevalence of sleepwalking in the elderly population studied was $6.9 \%$ (Table 7). It was found to correlate negatively with increasing BM I $(\mathrm{p} \varangle 0.041)$ and ageand positively with rising socio-economic strata $(p \varangle 0.076)$.

\section{Condusions}

It may beconcluded from theobservation sof thisstudy that common sleep problems are prevalent in a largeproportion of the elderly subjects of our community. N one of these individuals sisundergoing any form of treatment for thesame. It is likely that most of these subjects may be taking such problemsasa part of growing old. Thereis, therefore, a need to create awareness about sleep disorders in this segment of society in general, and people of thisagegroup in particular, as well as among themedical community that isengaged in theheal thcare of the elderly. Thereisalikelihood that these sleep disorders are having an impact on the quality of life, morbidity and mortality in this segment of thepopulation. It is, thus, imperative that future studies should focus on studying the impact of sleep disorders on the qual ity of life, morbidity and mortality in theelderly subjects.

Indian Journal of Sleep M edicine (IJSM ), Vol. 4, N o. 1, 2009 


\section{References}

1. Suri JC, Sen MK, Adhikari T. Epidemiology of sleep disorder in school children of Delhi: A Q uestionnaire Based Study. Indian J Sleep Med 2008;3.2,42-50

2. Chervin $\mathbf{R}$ et al. Pediatric Sleep Q uestionnaire, University of Michigan (chervin@ med.umich.edu)

3. Douglass AB, Bornstein R,N ino-Murcia G, Keenan S, Miles L, Zarcon VP Jr. the Sleep Disorders Questionnaire. I: Creation and multivariate structure of SDQ. Sleep 1994; 17:160-7

4. Davies RJ O, Stradling JR. The epidemiology of sleep apnea. Thorax 1996;51:S65-S70.

5. Uliel S, Tauman R, Green field $M$ et al. Chest 2004;125:872-878.

6. American Academy of Sleep Medicine. International Classification of Sleep Disorders: Diagnostic and Coding Manual. 2nd ed. Westchester, IL: American Academy of Sleep Medicine, 2005.

7. Young T, Palta M, Dempsey J et al. The occurrence of sleep-disordered breathing among middle-aged adults. N Engl J Med 1993;328:1230-1235.

8. Ancoli-Israel S, Kripke DF, Mason W et al. Sleep apnea and nocturnal myoclonus in a senior population. Sleep 1981;4(4):349-358.

9. Ancoli-Israel S, Kripke DF, Mason W et al. Sleepdisordered breathing in community-dwelling elderly. Sleep 1991;14:486-495.

10. Hoch CC, Reynolds CF $3^{\text {rd }}$, Monk TH et al. Comparison of sleep-disordered breathing among healthy elderly in the seventh eighth, and ninth decades of life. Sleep 1990;13:502-511.

11. Young T, Shahar E, Nieto FJ et al. Predictors of sleepdisordered breathing in community-dwelling adults: the Sleep Heart Health Study. Arch Intern Med 2002;162(8):893-900.

12. Bixler EO, Vgontzas AN, Ten Have T, et al. Effects of age on sleep apnea in men.I. Prevalence and severity. Am J Respir Crit Care Med 1998;157 (1):144-148.

13. Dancey DR, Hanly PJ, Soong C, et al. Impact of menopause as the prevalence and severity of sleep apnea. Chest 2001;120(1):151-155.

14. Resta O, Caratozzolo G, Pannacciulli N et al. Gender age and menopause effects on the prevalence and the characteristics of obstructive sleep apnea in obesity. Eur J Clin Invest 2003;33(12):1084-1089.

15. Resta O, Bonfitto P, Sabato R, et al. Prevalence of obstructive sleep apnea in a sample of obese women: effect of menopause. Diabetes N utr M etab 2004;17 (5):296-303.

16. Young $\mathbf{T}$, Finn L, Austin D, et al. Menopausal status and

Indian Journal of Sleep M edicine (IJSM ), Vol. 4, N o. 1, 2009
Sleep-disordered Breathing in the Wisconsin Sleep Cohort Study. Am J Respir Crit Care Med 2003;167(9):1181-1185.

17. Harrington JJ, Lee-Chiong J r T. Sleep and older patients. Clin Chest Med 2007;28:673-684.

18. Cooke JR. Sleep disorders in the elderly. Psychiatr Times 2008;25(4):

19. Zamarron C, Gude F, O tero Y, Alvarez JM, Golpe, Rodriguez $J R$. Prevalence of sleep disordered breathing and sleep apnea in 50-70 years old individuals - A Survey. Respiration 1999;66:317-322.

20. Ohayon MM, Roth T. Prevalence of restless legs syndrome and periodic limb movement disorder in the general population. J Psychosom Res 2002;53(1):547-554.

21. Phillips B, Young T, Finn L, etal. Epidemiology of restless legs symptoms in adults. Arch intern Med 200;160(14): 2137-2141.

22. Hornyak M, Trenkwalder C. Restless legs syndrome and periodic limb movement disorder in the elderly. J Psychosom Res, 2004;56:543-548.

23. Rothdach AJ, Trenkwalder C, Haberstock J, etal. Prevalence and risk factors of RLS in an elderly population. The MEMO study. Memory and Morbidity in Augsburg Elderly. Neurology 2000; 54(5):1064-1068.

24. Foley DJ, Monjan AA, Brown SL et al. Sleep complaints among elderly persons: an epidemiologic study of three communities. Sleep 1995;18(6):425-432.

25. Sateja MJ, Doghramji K, Hauri PJ, et al. Evaluation of Chronic Insomnia: An American Academy of Sleep Medicine review. Sleep 2000;23(2):243-308.

26. Foley DJ, Monjan AA, Simonsick EM et al. Incidence and remission of insomnia among elderly adults: an epidemiologic study of 6,800 persons over three years. Sleep 1999;22(Supp 2): S366-372.

27. Foley $\mathbf{D}$, Ancoli-Israel S, Britz $P$ et al. Sleep disturbances and chronic disease in older adults: results of the 2003 National Sleep Foundation Sleep in America Survey. J Psychosom Res 2004;56(5):497-502.

28. Espiritu J RD. Aging-related sleep changes. Clin Geriatr Med 2008;24-1-14.

29. Ohayan MM, Carskadon MA, Guilleminault C, Vitiello MV. Meta-analysis of quantitative sleep parameters from childhood to old age in healthy individuals: developing normative sleep values across the human life-span. Sleep 2004;27:1255-1273.

30. Swift CG, Shapiro CM. Sleep and sleep problems in London elderly people. In Shapiro CM Ed. ABC of sleep Disorders, BMJ Publishing Group 1993;37-40.

31. Salvio MA, Wood J M, Schwartz JA, Eichling PS. Nightmare prevalence in the healthy elderly. Psychol Aging 1992;\&:324-325.

32. Berlin RM, Q ayyum U. Sleepwalking: diagnosis and treatment through the life cycle. Psychosomatics 1986; 27 : 755-760. 